\title{
Coulisses
}

Revue de théâtre

13 | Hiver 1996

Varia

\section{Une critique en forme : « le public heureux dit merci »}

\section{M.C. Quilichini}

\section{(2) OpenEdition}

1 Journals

Édition électronique

URL : http://journals.openedition.org/coulisses/4270

DOI : $10.4000 /$ coulisses.4270

ISSN : 2546-9460

\section{Éditeur}

Presses universitaires de Franche-Comté

\section{Édition imprimée}

Date de publication : 1 janvier 1996

Pagination : 66

ISSN : 1150-594X

\section{Référence électronique}

M.C. Quilichini, « Une critique en forme : «le public heureux dit merci » », Coulisses [En ligne], 13| Hiver 1996, mis en ligne le 15 mars 2019, consulté le 04 octobre 2020. URL : http://journals.openedition.org/ coulisses/4270 ; DOI : https://doi.org/10.4000/coulisses.4270

Ce document a été généré automatiquement le 4 octobre 2020.

Coulisses 


\title{
Une critique en forme : « le public heureux dit merci »
}

\author{
M.C. Quilichini
}

1 Je n'étais pas seule, hier soir, à 'Opéra Théâtre de Besançon. C'est devant une salle comble que la compagnie Brozzoni offrait son récent spectacle La grande Parade au Cabaret de l'Ange bleu.

S'appuyant sur six des vingt-quatre scènes que compte Grand'peur et misère $\mathrm{du} \mathrm{III}^{e}$ Reich de Bertolt Brecht, cette troupe fantastique, formée de dix comédiens-chanteurs, de huit musiciens et de leur chef d'orchestre nous régale les yeux, les oreilles et l'esprit d'un spectacle total, grave et joyeux, profond et ironique à la fois.

2 Texte, musique, chansons s'enchaînent à un rythme continu, l'Allemagne des années trente revient à nos mémoires et nous découvrons Brecht sous un angle abordable pour ceux qui l'ignoraient, et dans un style rajeuni pour ceux qui le connaissaient déjà.

Ici, Brozzoni et la compagnie ont écarté la routine ; c'est un théâtre généreux, qui veut toucher tous les publics intensément, quitte à déranger ceux et celles dont la vision de Brecht est plus élitiste.

Dès l'ouverture du rideau, c'est l'étonnement: l'orchestre est situé face au public à quelques deux mètres de hauteur, légèrement en retrait par rapport aux comédiens. Ainsi, les musiciens participent totalement à cette parade.

3 La musique originale, composée par Etienne Perruchon pendant le travail des répétitions, donne à l'ensemble une parfaite cohésion. Le chef d'orchestre, Patrick Souillot, d'origine bisontine, a été notamment l'assistant de Léonard Bernstein ; il mène avec bonheur ses excellents instrumentistes, obtenant le meilleur de chacun.

Dès la première scène de cabaret, populaire et musicale, nous sommes transportés dans l'expressionnisme allemand. Le ton est donné, avec audace et ironie. Les textes et les chansons se succèdent à un rythme très rapide (les comédiens ont dix, quinze secondes pour se changer ou changer de personnage) et tous ces comédiens et musiciens, éclatant de jeunesse, de talent, d'enthousiasme nous entraînent à travers la dureté, la lâcheté, la "grand'peur » et la misère des années trente à Berlin. Ce pourrait être tragique, mais la forme de cette grande Parade nous ramène sans cesse à la jeunesse, à 
l'impertinence et à l'énergie de vivre. La dérision de ces artistes combat la déraison d'un peuple.

Je voudrais citer tous les comédiens, tous les musiciens; chacun est remarquable de maîtrise, de professionnalisme, tout en donnant une grande impression de liberté. Le travail d'équipe est parfait, sans aucun temps mort.

Les décors variés, très évocateurs, nous transportent sans décalage d'une scène de cabaret à une scène de rue, en passant par un appartement petit bourgeois. Les cent costumes situent parfaitement les comédiens dans chaque scène.

4 A la fin de La Grande Parade au Cabaret de l'Ange Bleu, de nombreux applaudissements et rappels ont salué chaleureusement la compagnie Brozzoni: tous les sentiments humains étaient passés, de l'émotion au sourire et au rire, cette vision de Bertolt Brecht avait donné à chacun à réfléchir, sans imposer un choix, et le public heureux disait merci.

\section{AUTEUR}

M.C. QUILICHINI

Spectatrice 